\title{
Team Models in Interfacility Transport-Building and Maintaining Competencies
}

\author{
Hilary E. Whyte, $M B, M S C, F R C P(I), F R C P(C)^{1, *}$ \\ Michael Narvey, MD, FRCPC, FAAP ${ }^{2}$
}

\author{
Address \\ *,1 Medical Director, Acute Care Transport Service, The Hospital for Sick Children, \\ University of Toronto, 555 University Avenue, Toronto, 0N, M5G 1X8, Canada \\ Email: hilary.whyte@sickkids.ca \\ ${ }^{2}$ Section Head Neonatology, Medical Director, Child Health Transport Team, 820 \\ Sherbrook St, Winnipeg, MB, R3A1R9, Canada
}

Published online: 8 November 2017

C Springer International Publishing AG 2017

This article is part of the Topical Collection on Transport Medicine

Keywords Interfacility transport $\cdot$ Transport teams $\cdot$ Mobile intensive care $\cdot$ Safety and system design

\section{Opinion statement}

Purpose of review Transport teams have evolved their capability to provide mobile intensive care units to optimize patient outcomes in most regionalized systems of health care. Our goal was to review the current literature to determine the best model of practice for interfacility transport and the specific training required to achieve and maintain competencies in transport medicine.

Recent findings The literature remains largely consensus based and experiential, and there has been little development in the 'state of the art' over the past 5 years. Transport practitioners, regardless of their professional backgrounds, must acquire numerous skills to meet the needs of the patient, owing to the unique and dynamic nature of each transport. The broader their scope of practice, the larger the range of competencies they must acquire. A critical volume of patients is required to maintain standards and performance especially for technical skills. Thus, teams should be specialized in the care of specific patient populations, as well as the field of transport processes, safety, and system design.

Summary For teams to be dedicated to the transport service, we often need to combine neonatal, (with or without high-risk mothers) with paediatric volumes, to ensure a critical mass of patients to build and maintain competencies. Ideally, a collaborative practice team model is created to facilitate this, with clinicians from different health care backgrounds and areas of practice. This permits the collective sum of its members' individual skills and abilities, facilitates cross training of all, and provides maximum flexibility for the team. Teams should be located at tertiary level hospitals for ready access to education and practical skills but should be centrally coordinated and dispatched for greatest efficiencies, and integration of air and land modalities. 'On-line' medical control provided by an experienced consultant and expert in transport medicine, together with transport policies 
and procedures, must be in place to guide performance and ensure optimal outcomes. Regular debriefing, extensive transport reviews, and a database help determine each individual's educational needs. Trends in key team performance indicators allow for benchmarking and help drive better performance.

\section{Introduction}

In the 1970s, the need for interfacility transport services became the most apparent with the advent of regionalised health care for high-risk mothers, newborns, and children. Demonstrations of enhanced outcomes, including mortality and morbidity, in resource-rich countries, resulted in recommendations for high-risk mothers (e.g. threatened preterm labor) and critically ill newborns and children, to be moved to tertiary care centers. The need for specialised interfacility transport teams became obvious as the 'instrument' of this regionalised care, when patients were arriving at the tertiary facilities in poor shape. We sought to examine the more recent literature on the topic of specialization in these transport teams, models of team, and building and maintaining team competencies. A search in MEDLINE Epub Ahead of Print, In-Process and other
Non-Indexed Citations [Ovid], MEDLINE(R) $<1946$ to Present $>$ was conducted focusing especially in the past 10 years. The search strategy included subject headings (MeSH) and text words for the concepts: transport team models, transport team training, competencies in transport medicine, intramural or intra-hospital transportation of newborn, premature, high-risk pregnancy or in-utero patients, ambulance, and air medical transport. Truncation symbols were used with the text words, when appropriate, to capture variations in spelling and word endings. The search results were limited to the English language and yielded over 500 articles. We reviewed key articles published in that time frame with a more in-depth review of publications since 2013. A few key articles in the reference list are designated with asterisks.

\section{Background}

The need for regionalization in health care was reinforced by the Institute of Medicine in 2007. Many countries recommend transfer of high-risk mothers to a tertiary setting [1•] to avoid 'outborn' deliveries and their attendant increase in mortality and morbidity $[2,3,4 \bullet \bullet]$. Despite the variations seen in patterns of regionalisation [5] and variations in transport systems [6•], the need for an interfacility transport service is rarely disputed, especially for neonates. When mothers cannot be moved to deliver, infants do better when transport teams are present at their delivery $[7,8 \bullet]$. The social security act dictates that there must be no reduction in the level of care during patient transport [9•]; patients require both clinical and transport expertise. However, the importance of that service being specialised to specifically meet the needs of the patient population is still debated. Belway and Chang on two systematic reviews both failed to find any evidence for

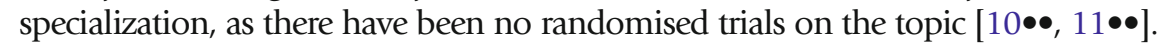

Older studies from the Netherlands [12] and USA [13] in paediatrics demonstrated enhanced care by specialised teams, and several prospective 'before and after' studies showed significant decline (e.g. 34 to $12.5 \%$ ) in adverse events $[14,15]$. Improved mortality rates, OR 0.58 (0.39-0.87) for PICU patients [16], have not been a consistent finding, since other studies showed equivalent clinical outcomes for specialised vs nonspecialised teams although the patients transported by specialized teams were sicker and required more interventions [17]. Interestingly, although it took longer for the specialised teams to reach the 
patient bedside, this was not associated with worsening outcomes [18 • ]. Adverse events, however, during transport are very prevalent when nonspecialised teams are used and generally relate to the severity of illness, duration of transfer and the lack of experience of the personnel [19-21, 22•]. These 'nonspecialised teams' could be local paediatricians [12] although are most often adult focused EMS providers. A survey of paramedics in USA, reported that $72.5 \%$ dealt with paediatric patients and $71.8 \%$ were familiar with neonatal equipment [23•]. Concentrating training in 'specialised teams' regardless of their professional background will enhance exposure to sick patients to teach and better maintain competencies. Obviously, a critical mass of unstable neonatal and paediatric patients are necessary to develop the competencies for safe practice.

Failures of communication are found to be responsible for the majority of serious safety events resulting in adverse patient outcomes [24]. Transport teams are prone to communication breakdown at every phase of the transport process, especially at time of hand over between teams [25]. A structured format or communication tool should be taught and always used to enhance transfer of accurate and complete information [26]. Many transport programs have adopted the SBARR (Situation, Background, Assessment, Recommendations, Readback) tool which had its' origin in nuclear submarine handoffs and has been shown to reduces errors. SBARR use in team call-backs for medical orders

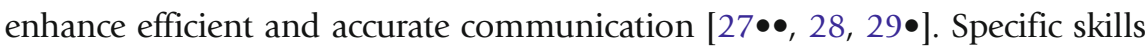
are required for the transfer 'call center' [30]. Communication with families must be handled with utmost sensitivity and tact focusing where possible on keeping parent and child together. Joyce informs us how certain factors influence family presence on transport. Parents were four times more likely to attend on land vs. air ( 26.6 vs $6.3 \%$ ) missions; $51 \%$ described enhanced anxiety; $26 \%$ of families felt unwelcome [31].

The more recent development of networks of transport providers permits benchmarking and learning from shared best practices. The Canadian Neonatal Transport Network was established in 2014, and is one example with membership of all 16 teams offering specialised neonatal transport in Canada. Teams which transport both neonatal and paediatric patients have a keen desire to expand this network to include all critical paediatric transports. As some teams in Canada are paediatric specific, their inclusion would also be crucial. The paediatric transport leadership seems willing to join a Canada-wide network permitting an opportunity for important comparisons. This would surely provide some insights into the questions posed in this manuscript. We could compare and contrast efficiency and outcomes of transported patients using a dedicated transport service vs and ad hoc unit-based response; the optimal configuration of health care personnel comprising the transport team or the impact of having a physician present or the patient population in which a physician might make an impact.

\section{What is the best model for specialized teams and their scope of practice?}


as with the American based Commission on Accreditation of Medical Transport Systems [32•] or Accreditation Canada [33], or College of Intensive Care Medicine of Australia and New Zealand [9]. Published standards for ambulances, e.g. the Q-Mentum standards for EMS [34], or the National Highway Act [35] do include our populations and recommendations for team composition. Several handbooks include recommendations for neonatal and paediatric land and air ambulance transport teams and have been published to guide the developing team on supplies, equipment, process, and system design. All are

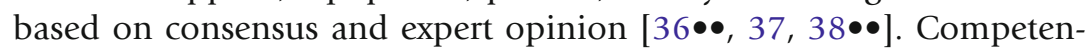
cies are also outlined but since the qualifications of personnel and transportation equipment [39] are not further defined in law or regulation, this is very open to interpretation and variation. This emphasizes the importance of quality assurance programs with key performance indicators (KPIs) with a shared composite data dictionary to be used across all teams. Networks established to bench mark their ac-

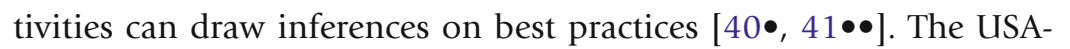
based GAMUT (Ground and Air Medical Quality Transport Improvement Collaborative) report on 12 core metrics directed at effectiveness, safety, efficiency, family centeredness, and timeliness. They include first attempt ETI success rates, unplanned device dislodgement, medicinal administration errors, hypothermia, crew and patient injuries, family accompaniment, and average mobilization times [42•].

The optimal composition of the specialised transport team remains elusive with all possible models of care having been described for both neonatal and

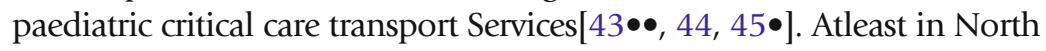
America, an RN/RN team is less costly than other models until the number of transports exceeds 2760 annually, at which point an EMT paramedic team becomes least costly [46]. Teams vary widely in their professional composition, but also location and availability. Some are dedicated to transport retrievals, while others are trained in transport but work at bedside until tasked on a transport 'mission'. Dedicated transport teams, rather than NICU/PICU staff on-call for transport, enhance availability and improve mobilization and response times [47]. Most teams consist of two people: an $\mathrm{RN}$ with either a paramedic or RT or MD. Although competent in the transport role [48], nurse practitioners have not gained wide acceptance in the North American/Canadian context but are increasingly seen where RTs are unavailable and doctors in short supply [49].

Answering the question of whether the composition of a transport team should include a physician is a challenging one. Descriptive studies of teams without physicians in the field have demonstrated acceptable outcomes in terms of procedural success and stable patient conditions at arrival in the receiving centre [50]. Unfortunately, whether the addition of a physician (which has been shown to be inefficient from a cost standpoint) improves on these outcomes has not been demonstrated in studies with a high level of evidence $[7,51,52]$. For the populations in question, many centres have phased-out physicians as service providers, focusing instead on their essential 
role in triage and medical on-line control [53]. Intuitively, there may be circumstances where a physician may be asked to act as a direct service provider when the patient is deemed to be at high risk of mortality or injury, and also where direct observation of the patient by a physician is desired by 'on line' medical control. While this practice certainly occurs, to date no study has supported such practice and it remains one guided by judgement only.

McCloskey examined predictability of the need for a physician before and after transport of critically ill paediatric patients and showed $73 \%$ had no decision discrepancy [54]. Guidelines published by American College Critical Care Medicine have recommended an RN and MD for adult based retrievals [55]. This model is frequently seen in trauma services which are the most unpredictable retrievals of all and where an MD may be justified. Paramedic scope and EMS professionals were defined only a decade ago and do not really address the paramedic as a critical care provider [56]. They are not regulated health care professionals in many jurisdictions such as Ontario, Canada, which may account for discrepancies in how they are used. In contrast, in the United Kingdom, they are registered healthcare professionals, who often have degrees in paramedicine and practice according to specific guidelines. Exceptional competencies over and above their professional guidance standards include induction and maintenance of anaesthesia, procedural sedation, advanced cardiovascular management, and complex invasive interventions. Since these would be rare events, selected crews can be trained in order to concentrate exposure [57••].

However, Physician trainees, do require exposure to prehospital care and interfacility transport for College accreditation (ACGME.org). A USA-based survey showed neonatal transport exposure in only $43 \%$ pediatric residents of whom only $23 \%$ were evaluated as part of the training; paediatric transport exposure occurred in 55\% with $21 \%$ evaluated [58 ]. It would appear that with the passage of time, residents and fellows have less and less exposure to transport medicine [59•] which is alarming and must be a focus of education by the transport teams. Even a 1 hour teaching session given to critical care and emergency physicians improved their knowledge base when assessed 2-4 weeks later and clearly improved training on medicolegal aspects of transport [60]. Given that involvement of some physicians will be in the field and, more commonly, they provide medical control for the teams, a thorough understanding of the challenges and complexities of care in the transport environment is of paramount importance.

The team model and location is really dictated by patient scope and volumes of transports. By combining populations, higher volumes of patients will be retrieved, increasing the critical mass, permitting a dedicated team to function

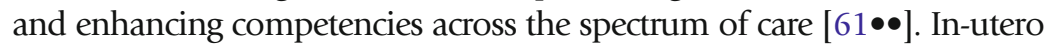
transport is clearly superior to transport of the unstable newborn with improved neonatal outcomes [62・]. Teams which can respond to both maternal as well as neonatal populations offer distinct advantages, since, although rare, an in-utero transfer may result in a birth where expertise in neonatal resuscitation will be an asset. Barker describes only 2 deliveries of 147 high-risk inutero transfers by land ambulance. This concurs with the older literature [63, 
64] reinforcing the much needed incentive to transfer high risk pregnancies to the nearest tertiary center. The addition of paediatrics to the scope along with maternal and/or neonatal transports virtually guarantees a dedicated transport team. Sufficient supply of critical patients to train and maintain competences while dealing with these distinct populations ensures both clinical

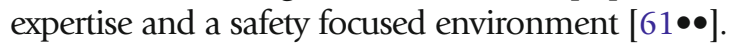

Telemedicine in transport may offer some enhancements to the abilities and scope of clinicians since visual as well as auditory contact with base hospital becomes feasible. Patel among others [24, 65] have demonstrated enhanced decision-making when using a video in addition to the teleconference [66•]. Triaging calls, when to transport, and by which team is more easily answered if the video conferencing capability exists at the referral sites rather than just with the team. Patel compared $1 \mathrm{PAB}$ and Facetime resulting in a decrease in transport duration (139 vs 186 minutes). A serious concern is the lack of compliance with Health Information and Privacy Act. In a survey of potential telemedicine users, $80 \%$ believe that these compromises are essential to best practice $[66 \bullet]$.

\section{What are the essential competencies for a maternal/neonatal/paediatric transport team?}

The Transport Competencies Profile presented on the CAPHC Knowledge Exchange Network (KEN) [67] provides a recommendation for a minimum set of standards for Canadian maternal, neonatal, and paediatric critical care transport teams. They were informed by an in-depth review of the challenges faced by transport teams in the field and can be used to guide education and practice of any interfacility transport team. They are summarized under the following seven categories:

Professional responsibilities: These include membership of their professional college, staying within scope of practice and legislation, ensuring patient privacy and confidentiality, ethical behavior, working as a team player, and participating in continuous learning, quality improvement, and research.

Communication: This competency includes skill in culturally sensitive, verbal, non-verbal and written communication, focusing on tact, discretion, compassion, and empathy. We have chosen to use SBAR $^{\circledR}$ as a means of standardized communication and documentation and it is widely used now in health care having been adapted from the Military Submarine and thenaviation industry.

Health and safety: Appropriate clothing and footwear must be worn to suit the environment and team identity. Maintaining mental and physical wellbeing is a responsibility of the clinician as well as personal protection against infectious diseases and infection control. Safe lifting and patient movement all fall under this competency.

Assessment and diagnostics: This should include training in comprehensive history taking, physical assessment including nutrition and fluids, psychiatric assessment, and obstetrical assessment. Laboratory and radiological diagnostics and interpretation will fall into this category also.

Therapeutics: These competencies encompass all required courses such as NRP, APLS, STABLE, and procedural sedation. Technical procedures, knowledge of devices and equipment, ventilation strategies, and pharmacology and toxicology are all extensively covered. 
Integration: A knowledge of growth and development is required to manage the patient. Integration of information into a problem list with differential diagnoses is practiced. Focus on referral and receiving teams as our clients, as well as the families we serve is included.

Transportation: The mode of transport, i.e. ground vs air ambulance is an important decision and requires specific expertise. Aside from availability and costs of air ambulances, considerations should also include availability and proximity of helipads, weather, traffic, size and weight of equipment, and number of team and family members. While the request is made by the team members, the decision is most frequently made by pilots independently and unaware of patient condition.

\section{Developing competencies: what are the characteristics of the successful transport clinician?}

Recruitment of appropriate personnel to the team is essential to success. Although no specific threshold of experience has been tested to predict better outcomes, it seems reasonable to have a minimum of 3 years of specialization in NICU, PICU, or PEM (paediatric emergency medicine) prior to joining the transport team as a base line. Better non-technical performance is seen in those with previous ICU or deployment experience [68]. Leadership qualities of flexibility, independence, critical thinking, and good judgment and problem solving with quick wit and intelligence, together with interpersonal and communication skills, favor good team and crisis resource management creating optimal team dynamics. Health and safety of the team are also of primary importance and should be considered when determining best model for team performance [69].

Transport clinician education programs should be built on the principles of adult learning theory, integrating concepts from behaviorism, cognitivism, and constructivism theory [70, 71]. Other frameworks that support the foundation of the education programs include Benner's Stages of Clinical Competence [72]. In this we take the student from 'novice', through 'advanced beginner', to 'competent' where they are able to demonstrate efficiency and confidence in actions, with patient plans based on conscious, abstract, analytic contemplation of the problem, proficiency, i.e. perceiving the situation as a whole, then on to 'expert' with fluid performance, flexibility, and high proficiency [72]. An outline of the program established at the Hospital for Sick Children, Acute Care Transport Service (ACTS) is shown in Fig. 1 with an overview of the core competencies acquisition in Table 1 . The ACTS team comprises an RN/RT model of care and transporting only tertiary level patients in the $0-13$ year age range and without the need for physician accompaniment. Once recruited, each member spends 1 year on contract, working as a 'transport associate', in order to determine their eligibility for further training as a transport clinician. The second year of intense training as a transport clinician is generally spent as outlined in the Fig. 2. The focus on mastering all cognitive and technical skills to meet the demands of the sickest patients is all consuming during this year with a continuous evaluation process. The final examinations occur through simulated neo-paeds scenarios followed by a minimum of six ride outs with senior staff consultants in Neonatal, Cardiac and 


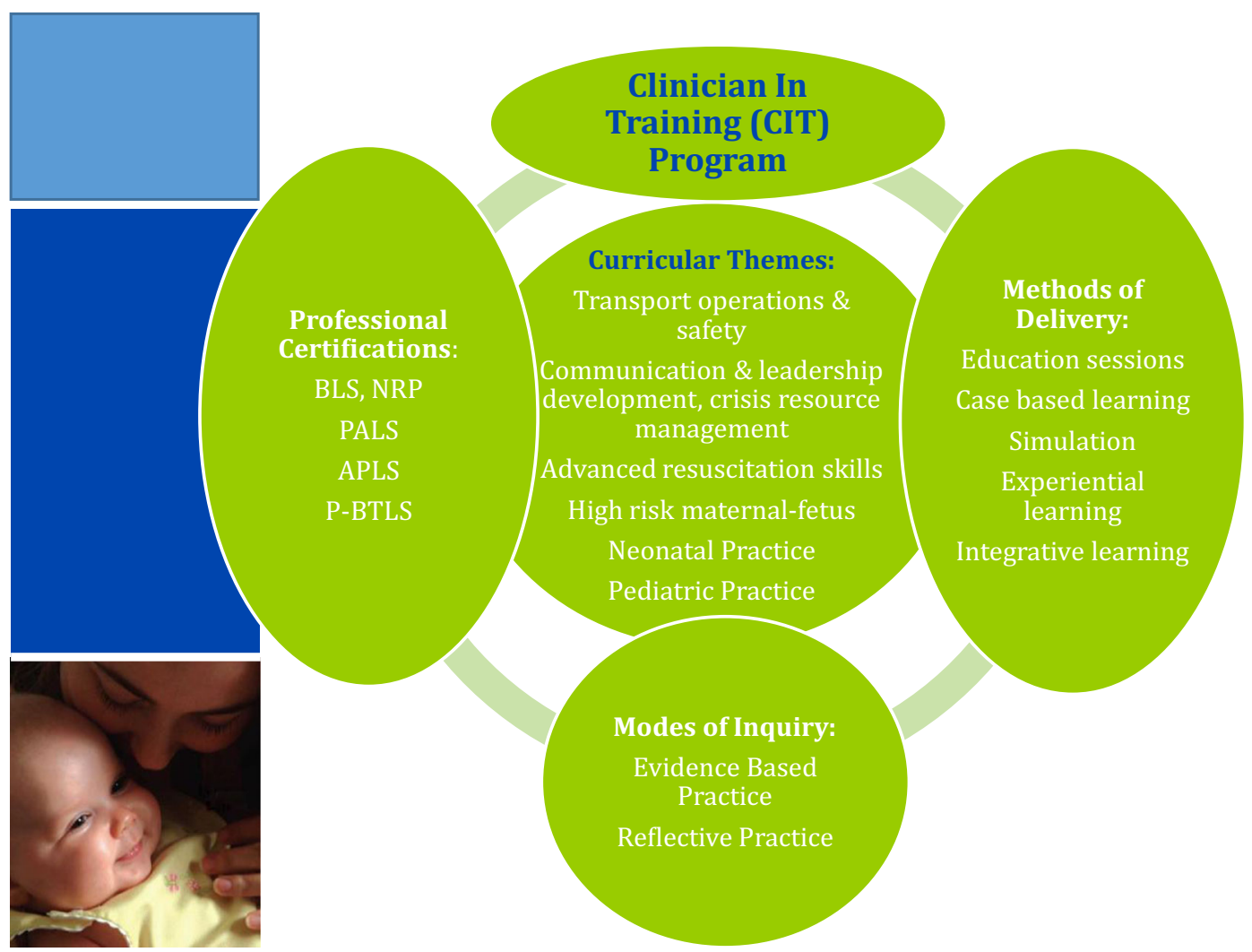

Fig. 1. SickKids Transport Clinician Training Program 2017. Courtesy of Annette Martens RN, BNSc, MN: Inter-Professional Education Specialist

Paediatric Intensive Care. All aspects of the training and evaluation are competency based and only those clinicians capable of independent practice and leadership will succeed in passing through the training program.

Our 'transport fellowship' aims to further educate fellows who have completed training in neonatal or paediatric intensive care or emergency medicine and who wish to specialize in transport medicine or gain more autonomy in practicing critical patient care. Following a 2-week 'bootcamp' each fellow spends a significant amount of time in a preceptored role supervised by an ACTS clinician before they are capable of independent practice in transport. The time to achieve full competency depends on their background and experience. They provide 'on-call' availability as an additional team member when a team requires extra hands for multiple births or patients in extremis. Other residents and fellows rotate onto the team for short periods to gain experience of the transport milieu. 


\section{Table 1. Core requirements of the Acute Care Transport Service (ACTS) team}

\begin{tabular}{|c|c|}
\hline $\begin{array}{l}\text { Core Clinical } \\
\quad \text { Certification(s) }\end{array}$ & $\begin{array}{l}\text { 1. NRP } \\
\text { 2. PALS } \\
\text { 3. BLS } \\
\text { 4. APLS } \\
\text { 5. PTLS } \\
\text { 6. Underwater survival training } \\
\text { 7. Winter survival training, STABLE Program asset }\end{array}$ \\
\hline $\begin{array}{l}\text { Equipment } \\
\text { Certification(s) }\end{array}$ & $\begin{array}{l}\text { 1. Neonatal Deck Configuration/Transport ventilator(s) \& Neonatal Intramural Deck Configuration- } \\
\text { Competency Based Assessment(s) (CBA) } \\
\text { 2. Inhaled Nitric Oxide e tutorial/CBA - indications, analyzer \& circuit delivery } \\
\text { 3. Pediatric Stretcher/ Transport Hamilton } T 1^{\oplus} \text { ventilator - e tutorial/CBA } \\
\text { 4. BBraun }{ }^{\circledR} \text { IV pump - CBA } \\
\text { 5. Point of Care Testing: I-stat }{ }^{\circledR} \& \text { glucose meter - I learn module } \\
\text { 6. Capnography I learn module } \\
\text { 7. Zoll }{ }^{\circledR} \text { patient monitor - e tutorial /CBA } \\
\text { 8. Defibrillator - e tutorial/CBA }\end{array}$ \\
\hline $\begin{array}{l}\text { Core Clinical \& } \\
\text { Technical Skills }\end{array}$ & $\begin{array}{l}\text { 1. Vascular \& Arterial Access/Sampling: peripheral intravenous insertion, umbilical venous and } \\
\text { umbilical arterial insertion, intraosseous needle insertion, peripheral arterial line } \\
\text { insertion/sampling/puncture, capillary blood sampling, SQ port access } \\
\text { 2. O/NGT insertion, urinary catheter insertion, invasive temperature } \\
\text { 3. Airway Management: positioning, suctioning/patency, oxygen/air administration, nasal } \\
\text { prong-low/high flow delivery, aerosolized mask administration, bag mask ventilation/CPAP, } \\
\text { oropharyngeal/nasopharyngeal airway insertion, supraglottic airway insertion, subglottic airway } \\
\text { device, intubation } \\
\text { 4. Non-invasive \& invasive ventilation with treatment modalities }\end{array}$ \\
\hline $\begin{array}{l}\text { Core Clinical \& } \\
\text { Technical Skills }\end{array}$ & $\begin{array}{l}\text { 5. Needle thoracentesis, chest tube insertion } \\
6 . \text { Cardioversion, defibrillation, pacing } \\
\text { 7. Neonatal therapeutic hypothermia, pediatric cooling } \\
\text { 8. Blood product administration } \\
\text { 9. Medication administration } \\
\text { 10. C-spine precautions \& motion restriction; support from expert health care staff } \\
\text { 11. Aero-medical physiology, transport safety training: } \\
\text { 12. Equipment/service, ground \& air transportation } \rightarrow \text { includes patient preparation \& transfer, } \\
\text { personnel safety }\end{array}$ \\
\hline \multicolumn{2}{|c|}{ Technical Skills Required \& Acquired } \\
\hline \multicolumn{2}{|c|}{$\begin{array}{l}\text { Skill set of Transport Associate plus } \rightarrow \text { intubation/LMA insertion, PAL insertion, umbilical line insertion, intraosseous insertion, } \\
\text { subcutaneous port access, needle thoracentesis and chest tube insertion, cardioversion/defibrillation/pacing }\end{array}$} \\
\hline Education hours & $\begin{array}{l}\text { Orientation: (integrated over duration of program - didactic, case based learning and simulation) } \\
\text { Total = } 100 \text { hours, } \\
\text { Additional hours for course certifications (APLS, BTLS, ED pediatric sedation \& ECG course, child } \\
\text { maltreatment course) } \\
\text { Additional hours for independent learning activities such as academic rounds, learning packages }\end{array}$ \\
\hline Clinical hours & $\begin{array}{l}\text { OR rotation }=24 \text { hours, Labour/delivery rotation }=36 \text { hours, ED rotation }=72 \text { hours, PICU/CCCU or } \\
\text { NICU rotation }=72 \text { hours, PICU/CCCU MD shadow shifts }=36 \text { hours } \\
\left.\text { NICU NNP mentor shifts }=36 \text { hours } \rightarrow \text { Total }=278 \text { hours ( }{ }^{*} \text { adjusted based on needs assessment* }\right) \\
\text { Transport clinical preceptorship }=9 \text { months ( } 1440 \text { hours) }\end{array}$ \\
\hline Evaluation & $\begin{array}{l}\text { Clinical evaluation by preceptors during training phases, assessments by educator \& medical } \\
\text { director/delegate, } \\
\text { Call back evaluations; monthly case reviews with physician(s), } 2 \text { written exams, advanced procedure/ } \\
\text { skills OSCEs, } \\
\text { High fidelity patient simulation OSCEs (on average } 4 \text { simulation cases) Field certification (average } 6 \\
\text { physician/educator observed transport retrievals) }\end{array}$ \\
\hline
\end{tabular}


recent review of training requirements followed assessment of their adult patient population and team experiences with serious safety events in

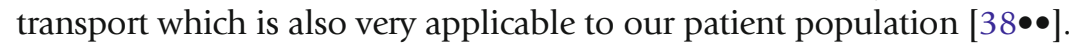
Studies have shown that technology or equipment failures are a particular problem and clinical problems including respiratory failure, hypothermia, hypoglycaemia, pneumothorax, hemodynamic instability, and respirator emergencies require specific attention during training schedules $[11 \bullet \bullet, 21$, 73•]. Generally, neonatal transfers require more interventions and have more complications compared to other populations [51]. In one study of 295 neonatal transfers, $19.8 \%$ of the neonates required intubation, compared to $7.5 \%$ of infants and $4.9 \%$ children; almost half of transport complications in neonates were airway related. Among EMS providers in Oregon with 11, 328 annual transports, only 497 were considered emergent (4.4\%). Airway issues occurred in 329 patients: $15.3 \%$ required bag and mask ventilation, $8.6 \%$ were intubated, and only $2 \%$ with a difficult airway. In their hands, $58 \%$ of intubations needed three or more attempts

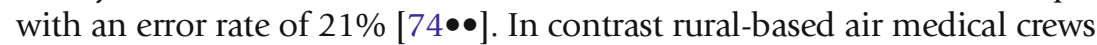
provided $85 \%$ of all intubations with a 95\% success rate [75].

The use of algorithms such as management of the difficult airway is recommended [69]. Training in advanced airway skills in the paramedic group seems to be a particular challenge [76]. Smith demonstrated that in

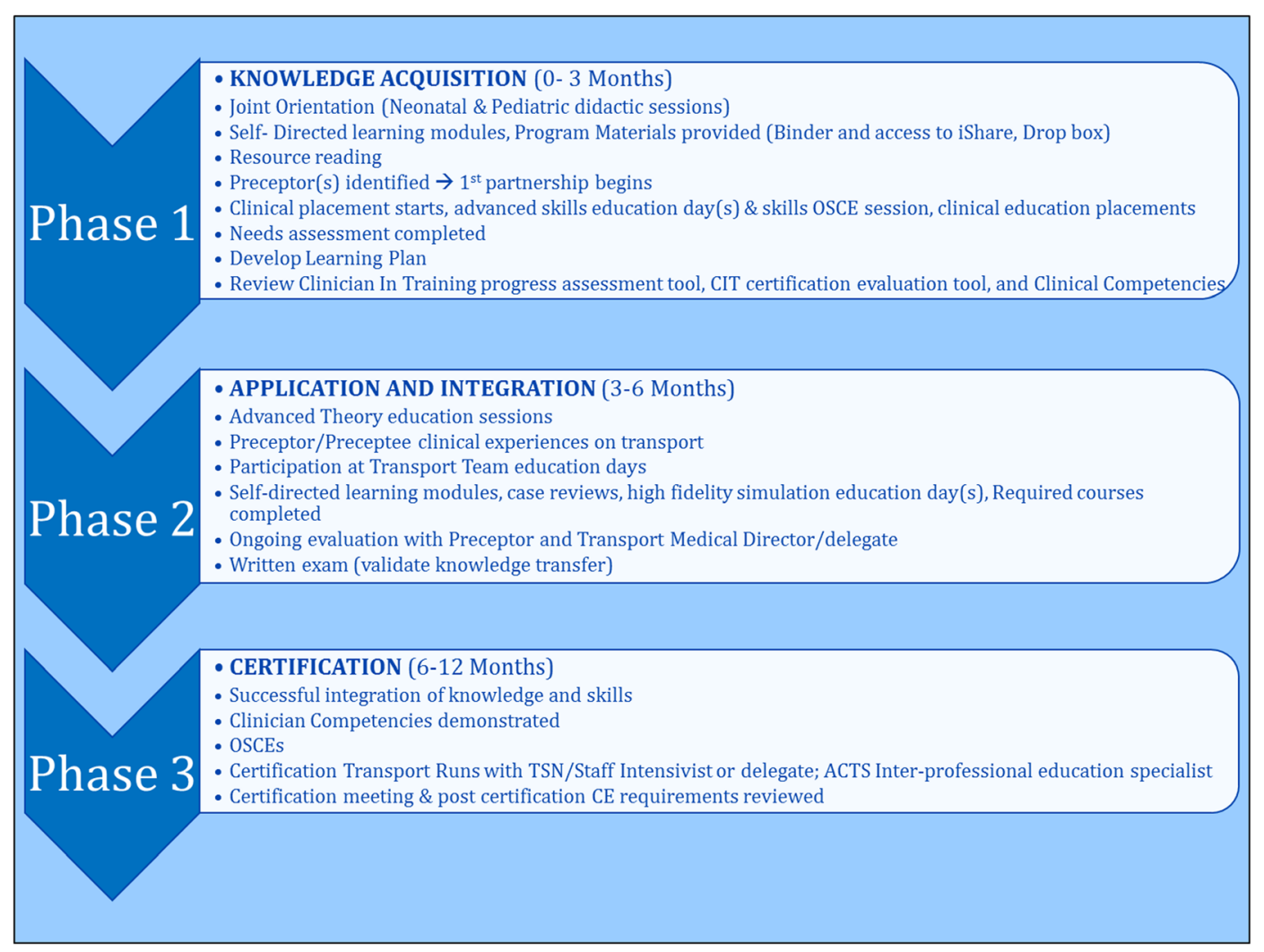

Fig. 2. Outline of Acute Care Transport Services (ACTS) Competency Based Training Program. Courtesy of Annette Martens RN, BNSc, MN: Inter-Professional Education Specialist 
167 intubations with $48 \%$ paediatric and $52 \%$ neonatal, multiple attempts were required in 30.4 and $69.6 \%$, respectively. The success rate increased with Rapid Sequence Induction (RSI) on the first attempt [77]. Video-assisted devices to facilitate intubation have been increasingly used and one recent study compares five such devices: AirTrac, Glidescope, AWS, C-MAC, and Coopdech VLP-100. The best/fastest model for the novice intubators was Pentax AWS [78•]. Although the operating room (OR) experience remains a gold standard for learning intubation, many have turned to simulation and task trainers as a necessary adjunct; high fidelity simulation is not superior [79]. In addition to task trainers, animal models may be helpful for teaching intubation and other procedural skills done infrequently, such as interosseous needle or chest tube insertion [80-82]. Campbell and others make a good case for using simulation training for transport teams, enhancing not only technical tasks but heavily focused on team work and communication skills [83, $84 \bullet \bullet, 85 \bullet$. While no studies relate specific training requirements to outcomes, repetition and training in simple procedures does lead to quality improvement $[86,87]$.

Education is the key to both recruitment and retention; feedback, self-assessment, mentorship, recognition, and annual retreats are all part of this strategy. Continuing education and skills practice are enhanced by continuous exposure within the hospital milieu [44]. Adult learners want self-directed learning and input into educational topics and accountability agreements regarding the structure of education. They want to develop their own learning modules, teach each other and non-transport staff, and participate in rural outreach. Adult learning is problem centered rather than content centered. Experience including mistakes provides the basis for learning activities [88]. The idea of forming human patient simulation networks with focus on continuing education and outreach will develop their role further [89]. Specifically, identified common case presentations should trigger establishment of clinical practice guidelines during transport and include specific goal-directed therapy which may result in better outcomes with reduced length of stay in PICU [90]. Annual written and oral assessments or objective structured assessment of technical skills, plus direct observation of patient care on 'ride outs' is encouraged [37].

\section{Compliance with Ethical Standards}

Conflict of Interest

Hilary E. Whyte and Michael Narvey declare no conflicts of interest.

Human and Animal Rights and Informed Consent

This article does not contain any studies with human or animal subjects performed by any of the authors. 


\section{References and Recommended Reading}

Papers of particular interest, published recently, have been

highlighted as:

- Of importance

- Of major importance

1. $\quad$ Kelly LE, Shah PS, Hakansson S, Kusuda S, Adams M, Lee SK, et al. Perinatal health services organization for preterm births: a multinational comparison. J Perinatol. 2017;37(7):762-8.

Perinatal services are reviewed across 11 high income countries most of whom have national recommendations for the transfer of high risk mothers and dedicated interfacility transport services.

2. Chien LY, Whyte R, Aziz K, Thiessen P, Matthew D, Lee $\mathrm{SK}$, et al. Improved outcome of preterm infants when delivered in tertiary care centers. Obstet Gynecol. 2001 Aug;98(2):247-52.

3. Lui K, Abdel-Latif ME, Allgood CL, Bajuk B, Oei J, Berry $\mathrm{A}$, et al. Improved outcomes of extremely premature outborn infants: effects of strategic changes in perinatal and retrieval services. Pediatrics. 2006

Nov;118(5):2076-83.

4.• Hossain S, Shah PS, Ye XY, Darlow BA, Lee SK, Lui K, et al. Outborns or inborns: where are the differences? A comparison study of very preterm neonatal intensive care unit infants cared for in Australia and New Zealand and in Canada. Neonatology. 2016;109(1):76-84.

This article continues to support the need for regionalization of health care for high risk mothers, newborns and children with best outcomes in those high risk infants born in a tertiary setting. 5. Zeitlin J, Papiernik E, Breart G, Group E. Regionalization of perinatal care in Europe. Semin Neonatol. 2004;9(2):99-110.

6. Eliason SH, Whyte H, Dow K, Cronin CM, Lee S, Canadian Neonatal N. Variations in transport outcomes of outborn infants among Canadian neonatal intensive care units. Am J Perinatol. 2013;30(5):377-82.

Differences in outcomes of the neonatal patients transported by different types of teams in Canada demonstrates the need for benchmarking and standardiztion of scope and practices where possible.

7. McNamara PJ, Mak W, Whyte HE. Dedicated neonatal retrieval teams improve delivery room resuscitation of outborn premature infants. J Perinatol.

2005;25(5):309-14.

8. $\quad$ McEvoy CG, Descloux E, Barazzoni MS, Diaw CS, Tolsa JF, Roth-Kleiner M. Evaluation of neonatal transport in Western Switzerland: a model of perinatal regionalization. Clinical medicine insights. Pediatrics.

2017;11:1179556517709021.

More emphasis on regionalization in health care with demonstration that 'outborn babies' did better when their delivery was attended by a transport team for the resuscitation and stabilization.

9. $\quad$ College of Intensive Care Medicine of Australia and New Zealand. Available from: http://cicm.org.au/. Offers standards focusing on logistics and clinical care.
10.• Belway D, Henderson W, Keenan SP, Levy AR, Dodek PM. Do specialist transport personnel improve hospital outcome in critically ill patients transferred to higher centers? A systematic review. J Crit Care. 2006;21(1):8-17. discussion -8 . More evidence that the literature is weak and only before and after studies provide evidence for specialised teams.

11.• Chang AS, Berry A, Jones LJ, Sivasangari S. Specialist teams for neonatal transport to neonatal intensive care units for prevention of morbidity and mortality.

Cochrane Database Syst Rev. 2015;28(10):CD007485.

This article reviews the literature and reinforces the lack of RCTs and thus lack of reliable evidence for specialised interfacility teams enhancing outcomes.

12. Vos GD, Nissen AC, Nieman FH, Meurs MM, van Waardenburg DA, Ramsay G, et al. Comparison of interhospital pediatric intensive care transport accompanied by a referring specialist or a specialist retrieval team. Intensive Care Med. 2004;30(2):302-8.

13. Edge WE, Kanter RK, Weigle CG, Walsh RF. Reduction of morbidity in interhospital transport by specialized pediatric staff. Crit Care Med. 1994;22(7):1186-91.

14. Ligtenberg JJ, Arnold LG, Stienstra Y, van der Werf TS, Meertens JH, Tulleken JE, et al. Quality of interhospital transport of critically ill patients: a prospective audit. Crit Care. 2005;9(4):R446-51.

15. Wiegersma JS, Droogh JM, Zijlstra JG, Fokkema J, Ligtenberg JJ. Quality of interhospital transport of the critically ill: impact of a mobile intensive care unit with a specialized retrieval team. Crit Care. 2011;15(1):R75.

16. Ramnarayan P, Thiru K, Parslow RC, Harrison DA, Draper ES, Rowan KM. Effect of specialist retrieval teams on outcomes in children admitted to paediatric intensive care units in England and Wales: a retrospective cohort study. Lancet. 2010;376(9742):698-704.

17. Meyer MT, Mikhailov TA, Kuhn EM, Collins MM, Scanlon MC. Pediatric specialty transport teams are not associated with decreased 48-hour pediatric intensive care unit mortality: a propensity analysis of the VPS, LLC database. Air Med J. 2016;35(2):73-8.

18. Patel SC, Murphy S, Penfil S, Romeo D, Hertzog JH. Impact of Interfacility Transport Method and Specialty Teams on Outcomes of Pediatric Trauma Patients. Pediatr Emerg Care. 2017. https://doi.org/10.1097/ PEC.0000000000001167.

This article demonstrates that although the patients waited longer, for transport by specialised teams, the outcomes were the same and the patients cared for by the specialsed teams were sicker. 
19. Kanter RK, Tompkins JM. Adverse events during interhospital transport: physiologic deterioration associated with pretransport severity of illness. Pediatrics.

1989;84(1):43-8.

20. Barry PW, Ralston C. Adverse events occurring during interhospital transfer of the critically ill. Arch Dis Child. 1994;71(1):8-11.

21. Wallen E, Venkataraman ST, Grosso MJ, Kiene K, Orr RA. Intrahospital transport of critically ill pediatric patients. Crit Care Med. 1995;23(9):1588-95.

22.• van den Berg J, Olsson L, Svensson A, Hakansson S. Adverse events during air and ground neonatal transport: 13 years' experience from a neonatal transport team in Northern Sweden. J Matern Fetal Neonatal Med. 2015;28(10):1231-7.

Highlights the risks involved in transports.

23. Raynovich W, Hums J, Stuhlmiller DF, Bramble JD, Kasha T, Galt K. Critical care transportation by paramedics: a cross-sectional survey. Air Med J. 2013;32(5):280-8.

This report from paramedics outlines the skill set which they require for critical care retrievals.

24. Kofos D, Pitetti R, Orr R, Thompson A. Telemedicine in pediatric transport: a feasibility study. Pediatrics. 1998;102(5):E58.

25. Lim MT, Ratnavel N. A prospective review of adverse events during interhospital transfers of neonates by a dedicated neonatal transfer service. Pediatr Crit Care Med. 2008;9(3):289-93.

26. Weingart C, Herstich T, Baker P, Garrett ML, Bird M, Billock J, et al. Making good better: implementing a standardized handoff in pediatric transport. Air Med J. 2013;32(1):40-6.

27.• Raymond M, Harrison MC. The structured communication tool SBAR (Situation, Background, Assessment and Recommendation) improves communication in neonatology. S Afr Med J. 2014;104(12):850-2.

The importance of communication and handoffs in transport medicine is underscored using the SBAR tool.

28. Lee SY, Dong L, Lim YH, Poh CL, Lim WS. SBAR: towards a common interprofessional team-based communication tool. Med Educ. 2016;50(11):1167-8.

29. Wilson D, Kochar A, Whyte-Lewis A, Whyte H, Lee KS. Evaluation of situation, background, assessment, recommendation tool during neonatal and pediatric interfacility transport. Air Med J. 2017;36(4):182-7.

Implementation of SBAR on transport is more successful with non MD professionals.

30. Newton SM, Fralic M. Interhospital transfer center model: components, themes, and design elements. Air Med J. 2015;34(4):207-12.

31. Joyce $\mathrm{CN}$, Libertin R, Bigham MT. Family-centered care in pediatric critical care transport. Air Med J. 2015;34(1):32-6.

32. Commission on Accreditation of Medical Transport Systems. Accrediation Standards.

Standards outlined.

33. Accreditation Canada 2013. Available from: https:// accreditation.ca.
34. Accreditation Canada. Emergency Medical Services QMentum.

35. National Highway Traffic Safety Administration. Guide for Interfacility Patient Transfer. . Available from: http://www.nhtsa.gov/people/injury/ems/interfacility/ images/interfacility.pdf.

36.• Guidelines for Air and Ground Transport of Neonatal and Pediatric Patients, 4th Edition: Elk Grove Village: Section on Transport Medicine AAP. Romito J, Alexander N. Edited by Insoft R, Schwartz H.

Likely still the best handbook on the market for Paediatric ground and air transport.

37. Martens A, Lee KS, Comar K, Silenzi L, O'Flaherty P, Harrold J, Laidlaw K, Rousom V, Whyte H, Maning M. Implementation and Evaluation of a Centralized Transport Clinician Training Program in Ontario. AAP National Conference and Exhibition, Section on Transport Medicine 2010.

38.• Droogh JM, Smit M, Absalom AR, Ligtenberg JJ, Zijlstra JG. Transferring the critically ill patient: are we there yet? Crit Care. 2015;19:62.

Although this article outlines the skills and competencies of required in adult critical care transport, it is a very comprehensive review of team requirements by outlining the incidents which occur during transport which then drive change.

39. Kempley ST, Ratnavel N, Fellows T. Vehicles and equipment for land-based neonatal transport. Early Hum Dev. 2009;85(8):491-5.

40. Bigham MT, Schwartz HP, Ohio Neonatal/Pediatric Transport Quality C. Quality metrics in neonatal and pediatric critical care transport: a consensus statement. Pediatr Crit Care Med. 2013;14(5):518-24.

The need for benchmarking using KPIsis outlined in this excellent article developed by the AAP scetion on transport medicine.

41.• Gunz AC, Dhanani S, Whyte H, Menon K, Foster JR, Parker MJ, et al. Identifying significant and relevant events during pediatric transport: a modified Delphi study. Pediatr Crit Care Med. 2014;15(7):653-9.

This paper describes a very robust process by which KPIs were developed by the Canadian Neonatal Transport Network (CNTN).

42.• Schwartz HP, Bigham MT, Schoettker PJ, Meyer K, Trautman MS, Insoft RM, et al. Quality metrics in neonatal and pediatric critical care transport: a National Delphi Project. Pediatr Crit Care Med. 2015;16(8):711-7.

Further reinforcement for the need for KPIs in transport evaluating effectiveness, safety, efficiencies and family centered care. Their 12 core metrics were developed by teams which were just neonatal ( $24 \%$ vs just paeds $9 \%$ vs combined team for neo-paeds $(61 \%)$.

43.• Tanem J, Triscari D, Chan M, Meyer MT. Workforce survey of pediatric interfacility transport systems in the United States. Pediatr Emerg Care. 2016;32(6):364-70.

This paper builds on the exemplary paper published by Karlsen et al in 2011 - below. 
44. Karlsen KA, Trautman M, Price-Douglas W, Smith S. National survey of neonatal transport teams in the United States. Pediatrics. 2011;128(4):685-91.

45. Kawaguchi A, Gunz A, de Caen A. Cross-sectional survey of canadian pediatric critical care transport. Pediatric emergency care. 2016. https://doi.org/10.1097/PEC. 0000000000000853

Highlights the significant disparity in paediatric transport systems across Canada and the lack of any specialised teams in many parts of the country.

46. Lee SK, Zupancic JA, Sale J, Pendray M, Whyte R, Brabyn D, et al. Cost-effectiveness and choice of infant transport systems. Med Care. 2002;40(8):705-16.

47. De Vries S, Wallis LA, Maritz D. A retrospective evaluation of the impact of a dedicated obstetric and neonatal transport service on transport times within an urban setting. Int J Emerg Med. 2011;4(1):28.

48. Leslie A, Stephenson T. Neonatal transfers by advanced neonatal nurse practitioners and paediatric registrars. Arch Dis Child Fetal Neonatal Ed. 2003;88(6):F509-12.

49. Davies J, Bickell F, Tibby SM. Attitudes of paediatric intensive care nurses to development of a nurse practitioner role for critical care transport. J Adv Nurs. 2011;67(2):317-26.

50. King BR, King TM, Foster RL, McCans KM. Pediatric and neonatal transport teams with and without a physician: a comparison of outcomes and interventions. Pediatr Emerg Care. 2007;23(2):77-82.

51. Beyer AJ 3rd, Land G, Zaritsky A. Nonphysician transport of intubated pediatric patients: a system evaluation. Crit Care Med. 1992;20(7):961-6.

52. Rashid A, Bhuta T, Berry A. A regionalised transport service, the way ahead? Arch Dis Child. 1999;80(5):488-92.

53. Thomas SH, Williams KA, Claypool DW. Air medical services task force of the National Association of EMSP Medical director for air medical transport programs. Prehosp Emerg Care. 2002;6(4):455-7.

54. McCloskey KA, Johnston C. Critical care interhospital transports: predictability of the need for a pediatrician. Pediatr Emerg Care. 1990;6(2):89-92.

55. Warren J, Fromm RE Jr, Orr RA, Rotello LC, Horst HM. American College of Critical Care M. Guidelines for the inter- and intrahospital transport of critically ill patients. Crit Care Med. 2004;32(1):256-62.

56. National Highway Traffic Safety Administration. The National EMS Scope of Practice Model. Available from: http://www.ems.gov/pdf/EMSScope.pdf.

57.• von Vopelius-Feldt J, Benger JR. Prehospital anaesthesia by a physician and paramedic critical care team in Southwest England. Eur J Emerg Med. 2013;20(6):382-6.

Adult patients but does identify competencies based on looking at data and professional guidance standards. clealry identifies differences in paramedic scope and competencies across the globe.

58. Kline-Krammes S, Wheeler DS, Schwartz HP, Forbes M, Bigham MT. Missed opportunities during pediatric residency training: report of a 10-year follow-up survey in critical care transport medicine. Pediatr Emerg Care. 2012;28(1):1-5.

Highlights need to be more proactive in including prehsopital care training in the curriculum of residents.

59. Mickells GE, Goodman DM, Rozenfeld RA. Education of pediatric subspecialty fellows in transport medicine: a national survey. BMC Pediatr. 2017;17(1):13.

Highlights the need for paediatric resident education in transport medicine.

60. Becker TK, Skiba JF, Sozener CB. An educational measure to significantly increase critical knowledge regarding interfacility patient transfers. Prehosp Disaster Med. 2015;30(3):244-8.

61.• Whyte HE, Jefferies AL, Canadian Paediatric Society F, Newborn C. The interfacility transport of critically ill newborns. Paediatr Child Health. 2015;20(5):265-75.

Previous review of literature on specialised transport teams including articles published up to 2014 with recommendations based on conscensus.

62. Barker CL, Costello C, Clark PT. Obstetric air medical retrievals in the Australian outback. Air Med ournal. 2013;32(6):329-33.

Highlights the need to focus on high risk maternal transport to avoid the need for neonatal transport.

63. Deutchman ME, Sills D, Connor PD. Perinatal outcomes: a comparison between family physicians and obstetricians. J Am Board Fam Pract. 1995;8(6):440-7.

64. Cifuentes J, Bronstein J, Phibbs CS, Phibbs RH, Schmitt SK, Carlo WA. Mortality in low birth weight infants according to level of neonatal care at hospital of birth. Pediatrics. 2002;109(5):745-51.

65. Spooner SA, Gotlieb EM, Committee on Clinical Information Technology, Committee on Medical Liability. Telemedicine: pediatric applications. Pediatrics. 2004;113(6):e639-43.

66. Patel S, Hertzog JH, Penfil S, Slamon N. A prospective pilot study of the use of telemedicine during pediatric transport: a high-quality, low-cost alternative to conventional telemedicine systems. Pediatr Emerg Care. 2015;31(9):611-5.

Outlines the advantages of using telemedicine to enhance transport advice calls resulting in decrease in call times but concerns raised about HIPA compatibility.

67.• Canadian Association of Paediatric Health Centres. Competencies profile-Interfacility critical care transport of maternal, neonatal, and paediatric patients 2011. Available from: https://www.caphc.org/ neonatalpaediatric-transport-systems/.

Although this reference dates back to 2011, it is likely one of the most comprehensive overviews of what is required for transport personel articulating 7 competencies with detialed explanation of what is required to meet those competencies.

68. Jernigan PL, Wallace MC, Novak CS, Gerlach TW, Hanseman DJ, Pritts TA, et al. Measuring intangibles: defining predictors of non-technical skills in critical care air transport team trainees. Mil Med. 2016;181(10):1357-62.

69. Practice guidelines for management of the difficult airway. A report by the American Society of 
Anesthesiologists Task Force on management of the difficult airway. Anesthesiology. 1993;78(3):597-602.

70. Bloom BS. Taxonomy of Educational Objectives, Handbook 1: The Cognitive Domain: David McKay Co Inc.; 1956

71. Merriam SBBLL. Adult Learning: Linking Theory and Practice. Hoboken: John Wiley and Sons Inc.; 2014.

72. Benner P. From Novice to Expert: Excellence and Power in Clinical Nursing Practice. Menlo Park: AddisonWesley; 1984

73.• Singh JM, Gunz AC, Dhanani S, Aghari M, MacDonald RD. Frequency, composition, and predictors of intransit critical events during pediatric critical care transport. Pediatr Crit Care Med. 2016;17(10):984-91.

Good review of adverse events during interfacility paediatric transports.

74.• Hansen M, Meckler G, Lambert W, Dickinson C, Dickinson K, Van Otterloo J, et al. Patient safety events in out-of-hospital paediatric airway management: a medical record review by the CSI-EMS. BMJ Open. 2016;6(11):e012259.

Good review of the incidence of management of airway and ventilation in the prehospital environment $58 \%$ of intubations required 3 or more attempts with an error rate of $21 \%$ for all interventions.

75. Henderson $\mathrm{K}$, Woodward LH, Isom KC, Wilson $\mathrm{J}$, Summers RL. Prevalence of intubation rescue by air medical personnel during transfers from rural emergency departments. Air Med J. 2015;34(3):141-3.

76. Lockey DJ, Healey B, Crewdson K, Chalk G, Weaver AE, Davies GE. Advanced airway management is necessary in prehospital trauma patients. Br J Anaesth. 2015;114(4):657-62.

77. Smith K, Gothard MD, Schwartz H, Guiliano J, Forbes $M$, Bigham M. Risk factors for failed intubation in paediatric and neonatal critical care specialty transport. Prehosp Care. 2015;19:1.17-22. https://doi.org/10. 3109/10903127.2014.964888.

78. Wallace MC, Britton ST, Meek R, Walsh-Hart S, Carter CTE, Lisco SJ. Comparison of five video-assisted intubation devices by novice and expert laryngoscopists for use in the aeromedical evacuation environment. Mil Med Res. 2017;4:20.

Good comparison of videoassisted devices for use in flight intubations comparing 5 different scopes.

79. Finan E, Bismilla Z, Whyte HE, Leblanc V, McNamara PJ. High-fidelity simulator technology may not be superior to traditional low-fidelity equipment for neonatal resuscitation training. J Perinatol. 2012;32(4):287-92.

80. Powell DA, Gonzales C, Gunnels RD. Use of the ferret as a model for pediatric endotracheal intubation training. Lab Anim Sci. 1991;41(1):86-9.

81. Hourihane JO, Crawshaw PA, Hall MA. Neonatal chest drain insertion-an animal model. Arch Dis Child Fetal Neonatal Ed. 1995;72(2):F123-4.

82. Anastakis DJ, Regehr G, Reznick RK, Cusimano M, Murnaghan J, Brown M, et al. Assessment of technical skills transfer from the bench training model to the human model. Am J Surg. 1999;177(2):167-70.

83. Cheng A, Donoghue A, Gilfoyle E, Eppich W. Simulation-based crisis resource management training for pediatric critical care medicine: a review for instructors. Pediatr Crit Care Med. 2012;13(2):197-203.

84.• Campbell DM, Dadiz R. Simulation in neonatal transport medicine. Semin Perinatol. 2016;40(7):430-7.

Excellent review article of utility of simulation in training transport teams.

85. Wong J, Finan E, Campbell D. Use of simulation in Canadian neonatal-perinatal medicine training programs. Cureus. 2017;9(7):e1448.

Outlines the need for using simulation to enhance critical care training especially in crisis resource management.

86. Britt RC, Novosel TJ, Britt LD, Sullivan M. The impact of central line simulation before the ICU experience. Am J Surg. 2009;197(4):533-6.

87. Hunt EA, Duval-Arnould JM, Nelson-McMillan KL, Bradshaw JH, Diener-West M, Perretta JS, et al. Pediatric resident resuscitation skills improve after "rapid cycle deliberate practice" training. Resuscitation. 2014;85(7):945-51.

88. Knowles M. The adult learner: a neglected species. 3rd ed. Houston: Gulf Publishing; 1984.

89. Cheng A, Hunt EA, Donoghue A, Nelson K, Leflore J, Anderson J, et al. EXPRESS-Examining Pediatric Resuscitation Education Using Simulation and Scripting. The birth of an international pediatric simulation research collaborative-from concept to reality. Simul Healthc. 2011;6(1):34-41.

90. Stroud MH, Sanders RC Jr, Moss MM, Sullivan JE, Prodhan P, Melguizo-Castro M, et al. Goal-directed resuscitative interventions during pediatric interfacility transport. Crit Care Med. 2015;43(8):1692-8. 